\title{
ANÁLISE DA SISTEMÁTICA DE CONTROLE INTERNO DO MUNICÍPIO DE TRẾS RIOS
}

\author{
INTERNAL CONTROL SYSTEMATIC ANALYSIS IN TRÊS RIOS MUNICIPALITY
}

\author{
Recebido em 14.05.2015. Aprovado em 04.10.2016 \\ Avaliado pelo sistema double blind review \\ DOI: http://dx.doi.org/10.12712/rpca.v10i3.594
}

\author{
Juscilei Carlos Henrique \\ juscileicarlos@hotmail.com \\ Universidade Federal Fluminense (UFF), Volta Redonda/RJ, BRASIL
}

\section{Leila Chagas}

leilarcead@gmail.com

Universidade Federal Fluminense (UFF), Volta Redonda/RJ, BRASIL

\section{Vanessa de Almeida Guimarães}

vanessaguim@hotmail.com

Universidade Federal Fluminense (UFF), Volta Redonda/RJ, BRASIL

\section{Ilton Curty Leal Junior}

iltoncurty@gmail.com

Universidade Federal Fluminense (UFF), Volta Redonda/RJ, BRASIL

\begin{abstract}
Resumo
Este trabalho versa sobre o controle em uma instituição pública municipal, com objetivo de verificar quais os mecanismos de controle interno adotados no município de Três Rios - RJ e se estes estão aderentes ao regimento legal. Além disso, analisou-se o perfil dos responsáveis pelos controles interno e externo e, especialmente, se eles compreendem a sistemática que os envolve. Por meio de entrevista, levantaram-se os mecanismos de controle interno adotados pela prefeitura e, pela aplicação de questionários, avaliou-se o controle externo exercido pela Câmara. Tendo em vista que os mecanismos de controle adotados são importantes para o desenvolvimento das atividades administrativas no município, pode-se notar que a prefeitura e a Câmara de Três Rios desempenham de forma satisfatória suas atribuições, mas há pontos a serem melhorados. Sugerem-se como soluções às principais limitações detectadas: o treinamento e contratação de pessoal e a criação de departamentos específicos para auditoria e controle.
\end{abstract}

Palavras-chave: Administração. Controle interno. Gestão Pública Municipal.

\section{Abstract}

This paper discusses the control in municipal public institution, aiming to verify which are the internal control mechanisms adopted in Três Rios - RJ and whether they are according to legal regulations. Besides, we sought to analyze the profile of the actors responsible for internal and external control and, specially, if they understand the systematic involving internal control procedures. Internal control mechanisms adopted by municipality were surveyed in a interview and, using questionnaires, we evaluate the external control exercised by Board of Alderman. Considering that the control mechanisms adopted are important to the administrative activities in this city, we noted that both municipality and Board of Alderman play satisfactorily their role, nevertheless there are gaps to improve. We suggest staff training and recruitment and a specific department to control and auditing as solution to the key-constrains identified.

Keywords: Administration. Internal control. Municipal Public Management. 


\section{Introdução}

A exigência cada vez mais ampla da sociedade de conhecer como os gestores públicos estão aplicando os recursos públicos torna o controle premissa básica para a verificação da correta utilização dos tributos pagos. De acordo com o artigo 37 da Constituição Federal de 1988, cumpre observar que todo ente estatal está submetido à obrigatoriedade de prestar contas de qualquer recurso que utilize, observando os princípios constitucionais da legalidade, impessoalidade, moralidade, publicidade e eficiência.

A Declaração dos Direitos do Homem e do Cidadão, de 1789, já prescrevia no seu artigo 15 que "a sociedade tem direito de pedir conta a todo agente público de sua administração". O dever de prestar contas é inerente a toda atividade pública e, sendo assim, tem-se como pressuposto que o controle interno é necessário para se garantir que a administração pública mantenha suas atividades sempre em conformidade com os referidos princípios encontrados na constituição e com as regras expressas nos atos normativos - tornando legítimos seus atos e afastando-os da nulidade.

$\mathrm{Na}$ administração pública municipal não poderia ser diferente, por isso, este artigo aborda os mecanismos de controle interno em uma instituição municipal. O controle interno surgiu da necessidade de assegurar o cumprimento das leis, normas e políticas vigentes, por meio do estabelecimento de mecanismos de controle que forneçam informações à sociedade, impedindo a ocorrência de fraudes e desperdícios, servindo de instrumento que visa garantir a efetividade, a produtividade, a economicidade e a rapidez na prestação do serviço público (Souza, 2008). Mas, para tanto, é importante que não apenas os responsáveis pelo controle interno, mas também aqueles que têm como incumbência o controle externo, compreendam a sistemática que o controle interno envolve. Isso, porque cabe ao controle externo verificar se a equipe responsável pelo controle interno está adotando os procedimentos adequados e atendendo a todas as previsões legais.

Este alinhamento entre as equipes e o conhecimento de todos os processos de controle se torna mais relevante em um município de pequeno porte, como Três Rios, pois há uma maior dificuldade em efetivar este controle, em função do montante de recursos disponíveis e dos responsáveis ocuparem cargos comissionados com maior rotatividade.
Assim, o problema de pesquisa que norteia este trabalho pode ser representado pelas seguintes questões: quais os instrumentos de controle interno aplicados a um município de pequeno porte? Estes estão baseados na previsão legal? Qual o grau de entendimento dos envolvidos (internamente e externamente) nesse processo?

Dessa forma, o presente estudo tem como objetivo principal compreender o sistema de controle interno da administração pública municipal de Três Rios. Como objetivos específicos, analisaram-se: (1) quais os procedimentos de controle interno adotados na prefeitura de Três Rios; (2) se os procedimentos adotados estão fundamentados na normativa legal; (3) qual o perfil dos atores envolvidos no processo de controle municipal interno e externo; (4) verificar se os responsáveis pelo processo de controle (interno e externo) compreendem a sistemática que o envolve.

O estudo se justifica pela possibilidade de demonstrar à sociedade fluminense, em especial a trirriense, a importância das ações do órgão de controle interno no acompanhamento da gestão municipal. Além disso, pode auxiliar na gestão do município estudado ao demonstrar que os mecanismos de controle interno adotados são importantes para o desenvolvimento das atividades administrativas da prefeitura. Permite, ainda, verificar se há necessidade de aprimoramento do controle interno existente na organização (ou se é adequado) e reforçar aos gestores sua importância, evitando erros e atendendo as demandas externas.

Portanto, o estudo mostra-se relevante do ponto de vista legal, uma vez que, a reforma administrativa de 1969 destacou a importância do controle e deixou clara sua função de proteção ao patrimônio público, por meio de normas voltadas para a fiscalização e o acompanhamento dos controles, registros, e aplicação dos recursos públicos, zelando e protegendo dessa forma, o gestor público, de penalidades e ações futuras, dos órgãos de fiscalização (Decreto-Lei n. ${ }^{\circ}$ 200/67).

Torna-se necessário enfatizar que esta investigação se restringe ao estudo da Secretaria de Controle Interno da prefeitura de Três Rios, que conta com outras 18 secretarias, por ser esta a responsável pela fiscalização de todas as outras. Além disso, não há pretensões de exaurir toda a problemática que envolve o tema, mas tão somente apresentar uma análise e uma maior reflexão e discussão do mesmo. 


\section{Referencial Teórico}

A origem do controle interno no Brasil, datada de 1914, era contábil, em função da necessidade de implantação de técnicas de contabilidade na área pública com certo nível de padronização de registro, orientação metodológica e controle dos atos de gestão em todos os níveis (Castro, 2008). Nesse período, segundo Silva (2004 apud Calixto \& Velásquez, 2005 , p. 4), "o controle interno atuava examinando e validando as informações sob os aspectos da legalidade e da formalidade", sendo que a sua preocupação se concentrava em atender aos órgãos de fiscalização externa e não à avaliação da forma como os administradores atuavam na prestação dos serviços públicos.

Em 1921, criou-se um órgão central de contabilidade da União denominada Diretoria Central da Contabilidade Pública que logo depois foi transformada em Contadoria Central da República e, finalmente, em Contadoria Geral da República. Com a estrutura contábil organizada, baseada fundamentalmente em informações para realização de balanços no setor público, o foco passou a ser técnico, aprovando-se o Código de Contabilidade Pública, que foi dividida em orçamentária, financeira e patrimonial, vinculada ao Ministério da Fazenda (Decreto do Poder Legislativo 4.536/1922). Uma vez estruturado o controle financeiro surgiu a necessidade de organizar o controle administrativo, preconizado pela Constituição Federal de 1946, que atribuiu ao Tribunal de Contas da União (TCU) o controle prévio dos atos de gestão do Executivo (Artigo 77 da Constituição Federal de 1946).

Pelo exposto, percebe-se que o controle interno seguiu duas linhas bem claras: controle contábil sob a responsabilidade do Ministério da Fazenda e controle administrativo sob a responsabilidade do TCU. Diante de um cenário de corrupção crescente e de instabilidade institucional deu-se origem ao regime autoritário de 1964, que mudou o foco do controle para auxiliar o dirigente público na obtenção de resultados planejados (Lei federal 4.320, de 17/03/1964).

A história do controle interno na administração pública brasileira está centrada no artigo 76 , da lei $\mathrm{n}^{\circ} 4.320 / 64$, que foi responsável pela introdução das expressões controle interno e controle externo e pela descrição de suas competências de exercício. Segundo Calixto e Velásquez (2005), foi conferido ao Poder
Executivo o controle interno, ao passo que o controle externo foi atribuído ao Poder Legislativo.

De acordo com esta lei, cabe ao Poder Executivo exercer os três tipos de controle da execução orçamentária: (i) a legalidade dos atos de que resultem a arrecadação da receita ou a realização da despesa, o nascimento ou extinção de direitos e obrigações; (ii) a fidelidade funcional dos agentes da administração responsáveis por bens e valores públicos; e (iii) o cumprimento do programa de trabalho expresso em termos monetários e em termos de realização de obras e prestações de serviços.

Nessa perspectiva, a referida lei definiu, primeiramente, a universalidade do controle, sua abrangência relacionada aos atos da administração, independentemente de se tratarda receita ou da despesa. Em seguida, o controle passou a contemplar cada agente da administração, de maneira individual, desde que apresentasse responsabilidade por bens e valores públicos. Contudo, a inovação central da lei surgiu no momento em que foi estabelecida a verificação do cumprimento do programa de trabalho, apresentado em termos físico-financeiros, o que significa que, pela primeira vez, concebia-se a possibilidade de controle de resultados na administração pública, além do controle de ordem legal (Calixto \& Velásques, 2005).

Di Pietro (2005) e Carvalho Filho (2009), definem o controle da administração pública como o poder de fiscalização e correção que sobre ela exercem os órgãos dos Poderes Judiciário, Legislativo e Executivo, buscando a garantia dos princípios norteadores do Estado Democrático de Direito: legalidade, impessoalidade, moralidade, publicidade e eficiência. Se a Administração Pública dá concretude aos objetivos do governo, naturalmente está vinculada ao atendimento do interesse público e ao cumprimento da lei. É nessa esfera de garantia de eficácia que se estabelecem mecanismos de controles, chamado controle da administração pública.

Existe abundância de conceitos de controles internos. Para ilustrar a magnitude acerca do tema, transcrevemse as seguintes definições adotadas por algumas entidades normatizadoras (Tabela 1). 
Tabela 1. Definições de Controle Interno

\begin{tabular}{l} 
FONTE \\
\hline COSO - Committee of Sponsoring \\
Organizations of the Treadway \\
Commission(1992). \\
\hline \\
INTOSAI - International Organization \\
of Supreme Audit Institutions (1992).
\end{tabular}

DEFINIÇÃO

Um processo operado pela administração e outras pessoas, desenhado para fornecer segurança razoável quanto à consecução de objetivos nas seguintes categorias: (a) confiabilidade de informações financeiras; (b) obediência às leis e regulamentos aplicáveis; (c) eficácia e eficiência de operações.

[...] um processo integral realizado pela gerência e pelos funcionários de uma entidade, desenhado para enfrentar os riscos e para garantir razoável segurança de que, na consecução da sua missão institucional, os seguintes objetivos serão alcançados: (a) execução correta, ética, econômica, eficiente e efetiva das operações; (b) cumprimento das prestações de contas; (c) cumprimento das leis e regulamentações; (d) garantia contra perdas, abuso ou dano dos recursos.

AICPA - American Institute of Certified O controle interno compreende o plano de organização e o conjunto coordenado Public Accountants (1954). dos métodos e medidas, adotadas pela empresa para proteger seu patrimônio, verificar a exatidão e a fidelidade de seus dados contábeis, promover a eficiência operacional e estimular a obediência às diretrizes administrativas estabelecidas.

CFC - Conselho Federal de O sistema contábil e de controles internos compreende o plano de organização Contabilidade (1997). $\quad$ e o conjunto integrado de método e procedimentos adotados pela entidade na proteção do seu patrimônio, promoção da confiabilidade e tempestividade dos seus registros e demonstrações contábeis, e da sua eficácia operacional.

IAIB - Instituto dos Auditores Internos do Brasil (1972).

Controle interno deve ser entendido como qualquer ação tomada pela administração (assim compreendida tanto a alta administração como os níveis gerenciais apropriados) para aumentar a probabilidade de que os objetivos e metas estabelecidas sejam atingidos. A alta administração e a gerência planejam, organizam, dirigem e controlam o desempenho de maneira a possibilitar com razoável certeza essa realização.

O conjunto de atividades, planos, rotinas, métodos e procedimentos Instrução Normativa $\mathrm{n}^{\circ}$ 01, de interligados, estabelecidos com vistas a assegurar que os objetivos das unidades $06 / 04 / 2001$ e entidades da administração pública sejam alcançados de forma confiável e concreta, evidenciando eventuais desvios ao longo da gestão, até a consecução dos objetivos fixados pelo Poder Público.

Analisando a definição de controle interno, é possível observar que estes podem ser segregados em: controles administrativos, que correspondem àqueles relacionados a atingir os objetivos da empresa, ao plano organizacional; e controles contábeis, que correspondem a todas as medidas necessárias para resguardar os ativos e o patrimônio da empresa (Crepaldi, 2007 e Attie, 2011)

De acordo com o tempo e a forma, o controle interno será classificado como: (1) prévio ou preventivo (a prior), quando ocorrer antes da conclusão do ato, com o objetivo de proporcionar segurança à sua execução; (2) concomitante, quando acompanha a execução do ato, com o objetivo de garantir a concretização da ação e (3) subsequente ou corretivo (a posteriori), quando é realizado após a conclusão do ato praticado, com o objetivo de avaliar a eficiência e eficácia dos atos administrativos, assim como corrigir possíveis erros. Todos têm como finalidade de garantir o alcance dos resultados esperados, reduzir riscos e preservar a responsabilidade dos dirigentes (Mossimann \& Fisch, 1999; Barreto, 2008; Castro, 2011).

Segundo Crepaldi (2007) e Castro (2011), a fim de normatizar o entendimento acerca das estruturas, normas e processos administrativos existentes nas ações dentro de qualquer entidade, faz-se necessário a obediência de princípios básicos que proporcionarão tal uniformidade (Instrução Normativa no 01, de 06/04/2001). São eles: a fixação de responsabilidade, a segregação de funções, o ciclo de uma transação, rigor na seleção do pessoal de controle, rodízio de pessoal, elaboração de manuais operacionais e utilização de processamento eletrônico. 
Dessa forma, o controle interno tem como objetivos: proteger os ativos, produzir os dados contábeis confiáveis e ajudar a administração na condução ordenada de suas atividades. Portanto, a partir de um consistente sistema de controle interno, procura-se evitar desvios, perdas e desperdícios; assegurando, razoavelmente, o cumprimento de normas administrativas e legais e propiciando a identificação de erros, fraudes e seus respectivos responsáveis.

A partir dessa concepção, o controle interno há de ser entendido como parte integrante da estrutura da administração pública, com o objetivo de auxiliar a gestão pública em relação ao cumprimento das metas e plano de governo.

Dessa forma, cabe mencionar que as atividades desempenhadas pelo controle interno e externo apresentam alguma similaridade quanto aos objetivos e técnicas aplicáveis, porém, se distinguem quanto à sua atuação. $\mathrm{O}$ controle interno integra a estrutura organizacional da administração, tendo por função acompanhar a execução dos atos e apontar, em caráter sugestivo, preventivo ou corretivamente, as ações a serem desempenhadas. Além disso, note-se o caráter opinativo do controle interno, haja vista que o gestor pode ou não atender à proposta que lhe seja indicada, sendo dele a responsabilidade e risco dos atos praticados.

Com relação ao controle externo, caracteriza-se por ser exercido por órgão autônomo e independente da administração, cabendo-lhe as atribuições indicadas pela Constituição Federal de 1988. Esse controle é exercido pelo Poder Legislativo, auxiliado pelos Tribunais de Contas, com o objetivo de verificar a probidade da administração, guarda e legal emprego dos dinheiros públicos e o cumprimento da lei.

Os controles interno e externo municipal são aqueles exercidos pelos Poderes Executivo e Legislativo, respectivamente. O Poder Executivo, aqui neste estudo, é representando pelo prefeito, vice-prefeito e seus secretários municipais, reconhecidos como agentes políticos, uma vez que assumem a obrigação de velar pela estrita observância aos princípios constitucionais e legais, na gerência dos recursos sob suas responsabilidades.

O Poder Legislativo é representado pelos vereadores eleitos, que são representantes do povo, devendo elaborar e aprovar normas que irão reger a vida da população local e o desenvolvimento municipal, bem como no desempenho da tarefa de fiscalização dos recursos públicos, ou seja, exercer o controle externo do Poder Executivo, isto é, da Prefeitura.

Dessa forma, é possível verificar o cumprimento da legislação no campo do controle interno municipal, observando se as atividades do dia a dia estão sendo planejadas e executadas com ajuda dos mecanismos vigentes, uma vez que o controle precisa ser efetivo, produtivo e econômico.

\section{Metodologia}

Este trabalho é considerado uma pesquisa aplicada, já que se caracteriza por ser um estudo sistemático motivado pela curiosidade intelectual, que tem por finalidade descrever os mecanismos de controle interno adotados pelos gestores em uma instituição municipal, bem como observar sua importância na gestão. Também é uma pesquisa empírica, pois o pesquisador precisa ir a campo, conversar com pessoas e presenciar relações sociais (Gil, 2008).

Quanto aos procedimentos técnicos, foi realizado um estudo de caso. Segundo Gil (2008), no estudo de caso investiga-se um fenômeno dentro do contexto da vida real, quando a fronteira entre o fenômeno e o contexto não é claramente evidente e onde múltiplas fontes de evidências são utilizadas. Já em relação à forma de abordagem, esta pesquisa é de cunho qualitativo embora sejam empregados instrumentos estatísticos descritivos, tanto na coleta como no tratamento dos dados.

O instrumento utilizado para a coleta de dados na prefeitura foi a entrevista semiestruturada com dez perguntas (embora outras tenham sido feitas decorrente da dinâmica de respostas) com o secretário de controle interno da Prefeitura de Três Rios, abordando a importância do controle interno na instituição. A entrevista durou cerca de 50 minutos e foi realizada no dia 23 de março de 2014, na sede da prefeitura, localizada na Praça São Sebastião, 81, Centro. A mesma foi gravada com a finalidade de não se perder nenhuma informação e, em seguida, transcrita e analisada. 
Já o instrumento utilizado para coleta de dados na Câmara de Vereadores foi um questionário com nove perguntas fechadas. Foram aplicados vinte questionários, correspondentes ao número total de servidores e agentes públicos que atuam na referida câmara, sendo: 7 (sete) da controladoria e 13 (treze) vereadores da Câmara de Três Rios, para que fossem respondidos no período de 11 a 18 de março de 2014. Os questionários foram entregues e recolhidos pelo próprio pesquisador, sendo que todos foram respondidos, representando assim a população total da pesquisa. Os dados obtidos foram organizados, tabulados, analisados para que subsidiar a discussão apresentada na Seção 4.

Utilizou o método de análise de conteúdo, pela avaliação dos questionários juntamente com os registros da entrevista realizada com o secretário, categorizando os assuntos expostos, confrontando com o problema da pesquisa e com o conteúdo explicitado na fundamentação teórica, alcançando-se, então, a conclusão (Almeida, 2011).

\section{Desenvolvimento}

Para facilitar a análise e discussão dos dados obtidos nesta pesquisa, optou-se por apresentar as informações em dois blocos: (1) controle do poder executivo municipal, o qual se refere ao controle interno e (2) controle do poder legislativo municipal, o qual se refere ao controle externo.

\section{Controle do poder executivo municipal}

Três Rios é um município brasileiro do estado do Rio de Janeiro. Sua população urbana aferida em 2010 pelo Censo é de 77.503 habitantes. Por ser cidadepolo (cidade que se destaca dentre os demais núcleos urbanos menores e exercem grande influência em seu entorno) da região centro sul fluminense, atrai visitantes de todos os municípios vizinhos e também de municípios de Minas Gerais em busca de empregos, comércio e lazer. A cidade, antes chamada de Entre Rios, foi elevada à categoria de município em 1938, chamando-se Três Rios.

A prefeitura conta com 19 secretarias, entretanto a pesquisa foi aplicada mais precisamente à Secretaria de Controle Interno (SCI). A SCI é um órgão situado no primeiro nível hierárquico da administração direta do Poder Executivo Municipal. Tem a seu encargo a atribuição de exercer a fiscalização contábil, financeira, orçamentária, operacional e patrimonial do município e das entidades da administração direta e indireta, quanto à legalidade, legitimidade, economicidade, aplicação das subvenções e renúncia de receitas.

A entrevista foi realizada com o secretário de controle interno, o Sr. Getúlio de Oliveira. O mesmo está no serviço público há mais de 26 anos e à frente da secretaria há cinco anos. Além das questões pré-elaboradas, no decorrer da entrevista outras informações foram sendo captadas, como forma de enriquecer o trabalho.

A primeira pergunta procurou identificar se o controle interno do município tem atuação pautada por Projeto de Lei, com aprovação na Câmara Municipal. O Sr. Getúlio informou que há uma lei especifica (a Lei no 2.302 de 24 de junho de 1999) que criou a Controladoria Geral e o Departamento de Licitações e Contratos Administrativos do Município de Três Rios. Com a atribuição de: (a) analisar a legalidade dos atos dos administradores municipais; (b) acompanhar a execução orçamentária financeira; (c) analisar e emitir parecer sobre as prestações de contas de adiantamento; (d) analisar e emitir parecer sobre editais, minuta de contratos e convênios, termos aditivos, reconhecimento de dívida; (e) analisar a legalidade e instrução processual dos processos licitatórios; (f) acompanhar, controlar e avaliar os programas de Governo, Plano Plurianual e dos orçamentos quanto à aplicação dos princípios da legalidade, legitimidade, economicidade e razoabilidade; orientar quanto à utilização do manual de normas e procedimentos; (g) promover o acompanhamento e a realização de auditoria sobre a execução orçamentária e financeira; (h) acompanhar e exercer controle, visando atingir metas fiscais de resultados primários e nominais; (i) efetuar acompanhamento e controle visando atingir os limites constitucionais.

A Secretaria de Controle Interno do município de Três Rios está hierarquicamente subordinada ao chefe do executivo (o prefeito) e diretamente ligada às outras 18 secretarias. Assim, ela é responsável por fiscalizar a atuação das outras secretarias, tendo como base as ações listadas no parágrafo anterior. Pode-se ressaltar que há observância ao conjunto de normas, rotinas e procedimentos, com finalidade de impedir o erro, a fraude e a ineficiência. 
Após verificar que o controle interno é exercido de forma independente e autônoma, perguntouse quantos profissionais são responsáveis pelas atividades. $O$ entrevistado respondeu que, além dele - secretário, existem mais nove servidores que o assistem nas atividades de controle. Ao levantar o questionamento sobre a formação profissional e técnica, foi constatado que $60 \%$ dos servidores têm nível superior, sendo quatro contadores (incluindo o secretário), um administrador e um advogado. Os outros $40 \%$ são de nível médio ou técnico. Logo, fazse necessário o rodízio e a segregação de funções.

O princípio da segregação de funções consiste em que um cargo/pessoa não tenha o domínio completo sobre uma determinada operação. É uma medida preventiva para que qualquer erro intencional ou não que este cometa possa ser detectado de imediato por outra pessoa (Attie, 2011).

Segundo relato do secretário, as principais atividades do controle interno estão ligadas à área financeira, em que são observados os procedimentos da contabilidade, pois qualquer tipo de projeto/programa necessitará de dotação orçamentária, recursos ou rubrica disponíveis, se há ou não necessidade de licitação. Além disso, há também o acompanhamento de todos os recursos. Nesse ponto, a prefeitura atua de acordo com o art. 54 da Lei de Responsabilidade Fiscal: o responsável pelo controle interno participa dos relatórios de gestão fiscal (controles de limites de despesas, empenhos e dívidas).

Para o secretário do controle interno, todos os procedimentos são muito claros, entretanto a dificuldade está em gerir tanta informação junta, pois há diversos normativos que devem ser seguidos. Tal afirmação é confirmada por Coelhos (2009), em que o agir é consoante com o princípio da legalidade, onde os agentes só podem e devem fazer aquilo que a lei obrigar ou expressamente autorizar, ou seja, quando a lei determina não é uma prerrogativa e sim uma obrigação.

Outra atividade levantada é a gestão dos convênios, onde se procura fazer a prestação de contas dentro do prazo, dadas as exigências do Tribunal de Contas do Estado do Rio de Janeiro (TCE-RJ). Foi questionado, então, se as atividades de controle eram apenas para atender às exigências externas. A resposta foi negativa, sendo ressaltado que há fiscalizações nos setores de forma preventiva e corretiva, pois é importante evitar erros e fraudes, bem como corrigir falhas existentes. O secretário ainda acrescentou que "O controle interno não controla o gestor, não engessa, nem impede sua atuação. Ao contrário, amplia sua visão, seu conhecimento de todos os meandros da administração, auxiliando a gestão municipal”.

Por fim, foram abordadas as limitações do controle interno dentro da prefeitura, destacando-se a falta de pessoal especializado, uma vez que, o controle interno é uma cadeia que necessita de pessoas na contabilidade, nas finanças, na auditoria, no orçamento. Ou seja, demanda uma gama de serviços que levam a necessitar de pessoas preparadas e bem treinadas. Além disso, há as limitações inerentes ao controle, que se justificam pelo fato de, na maioria dos procedimentos, poder ocorrer falhas resultantes de entendimento precário das instruções, erros de prejuízo, descuidos ou outros fatores humanos (Attie, 2011).

Para concluir, o secretário ressaltou que na gestão atual do prefeito Vinicius Farah (2012-2016) foram implementadas mudanças na Secretaria de Controle Interno que promoveram maior agilidade e eficácia em suas rotinas, entre elas: (a)reestruturação física e pessoal do setor; (b) criação do serviço de acompanhamento e controle de adimplência junto aos órgãos Federais e Estaduais; (c) acompanhamento e controle de convênios, contratos e afins; (d) acompanhamento e controle de repasse de recursos a entidades sem fins lucrativos; (e) treinamento específico para todos os funcionários junto à Escola de Contas e Gestão do Tribunal de Contas do Estado do Rio de Janeiro (ECG - TCE-RJ).

\section{Controle do poder legislativo municipal}

Para saber o perfil dos servidores e vereadores que atuam na Câmara de Três Rios foram feitas as seguintes perguntas: o tempo de atuação na Câmara, o setor em que atua e o tipo de cargo. Pode-se constatar que a maioria dos respondentes (60\%) que atuam na Câmara de Três Rios tem até 04 (quatro) anos de serviços prestados (vereadores) e apenas 15\% atuam a mais de 08 (oito) anos (servidores).

A maior parte dos servidores (55\%) atua no setor administrativo, enquanto $20 \%$ atua no setor jurídico e $25 \%$ no do setor contábil. Apesar de serem em menor número, o setor jurídico e contábil exercem 
de maneira adequada as suas atividades. Uma vez que, tanto o setor contábil quanto o setor jurídico são base para uma gestão eficiente.

A estrutura funcional da Câmara é composta em sua maioria por cargos comissionados, com $25 \%$, e que a minoria dos servidores são efetivos, com apenas $10 \%$ dos respondentes. Isso excluindo os vereadores que são agentes políticos, que correspondem por $65 \%$ dos cargos. Situação que pode levar a um não comprometimento com o órgão, pois o servidor comissionado pode ser exonerado do cargo que ocupa a qualquer momento.

Perguntou-se aos participantes se eles tinham conhecimento sobre o que seria o Sistema de Controle Interno: a maioria dos pesquisados $(75 \%)$ dizem saber o que é Sistema de Controle Interno, enquanto (25\%) informaram não saber.

Quando perguntados se sabiam qual a importância do Sistema de Controle Interno na Administração Pública, verificaram-se os seguintes dados: $30 \%$ dos respondentes declaram saber qual a importância do Sistema de Sistema de Controle Interno, 20\% não conhecem a importância, e 50\% dizem saber superficialmente. Fato que demonstra a necessidade do esclarecimento da importância do Sistema de Controle Interno para os servidores e vereadores, pois é por meio do Sistema de Controle Interno que os objetivos do órgão administrativo são alcançados e que se tem a garantia do equilíbrio entre autoridade $\mathrm{e}$ responsabilidade (Botelho, 2003; Castro, 2008).

Procurou-se saber dos participantes da pesquisa qual era a natureza do Sistema de Controle Interno (prevenir, detectar ou corrigir erros). Não houve diferença significativa de percentuais entre as respostas, porque todas estão corretas. Porém observou-se que as alternativas com maior número de respostas foram aquelas que indicam que a natureza do Sistema de Controle Interno é corretiva e/ou detectiva, ambas com 35\% das respostas. Embora a correção e/ou a detecção tenham alcançado os maiores percentuais, José Filho (2008) afirma que na Administração Pública o Sistema de Controle Interno deve estar presente de forma preventiva, em todas as suas funções na busca da realização dos objetivos a que se propõe.

Para conhecer a opinião dos participantes de como alcançar a eficiência na Administração Pública foram elaboradas quatro alternativas, todas corretas, porém só poderiam optar por uma delas. Verificou-se que somente $5 \%$ dos respondentes entendem que por meio da publicação dos atos executados existirá eficiência na Administração Pública. Enquanto que praticamente não há diferença entre os que optaram pela economia na realização da despesa e na observação da legalidade na execução dos atos. Entretanto a maioria dos participantes, com $45 \%$ das respostas optou que para alcançar a eficiência na Administração Pública deve-se treinar e capacitar os servidores. Segundo Campos et al (2010), por meio de treinamento os servidores terão informações quanto às leis e, consequentemente, compreenderão a importância de economizar ao realizar uma despesa, a observação da legalidade e a publicação dos atos praticados.

Considerando que na Administração Pública o conjunto de métodos adotados pelo Sistema de Controle Interno traz segurança e proporciona autenticidade às informações obtidas (Castro, 2008), foi perguntado aos participantes da pesquisa de que forma o Sistema de Controle Interno traz benefícios à gestão pública.

$\checkmark \quad 45 \%$ entendem que o maior benefício é promover a eficiência na entidade;

$35 \%$ apontam que é proporcionar segurança aos atos do gestor;

$\checkmark \quad 15 \%$ afirmam que é dar efetivo apoio ao Tribunal de Contas;

$\checkmark \quad 05 \%$ que é a valorização política dos administradores.

José Filho (2008) afirma que a eficiência operacional na entidade é alcançada através de meios que assegurem métodos e padrões adequados e voltados aos objetivos propostos, seja por seleção de pessoal qualificado, treinamentos, planos de carreira etc. Permitindo o desenvolvimento das funções de forma racional, harmônicas e integradas entre si.

Foi pedido aos respondentes que informassem qual a maior dificuldade em implantar um Sistema de Controle Interno. Percebeu-se que 60\% dos participantes entendem que a falta de esclarecimento quanto à importância do Sistema de Controle Interno é a principal dificuldade em implantá-lo. Em 
contrapartida, $40 \%$ disseram que o motivo se deve a economia, pois para ocupar o cargo de Controlador é ideal um servidor efetivo, precisando para isto da aplicação de concurso público. Entende-se com isto que a maioria acredita que se a importância do Sistema de Controle Interno fosse demonstrada, haveria a ocupação do cargo de controlador comissionado e, posteriormente, se aplicaria um concurso público para preencher a vaga destinada ao responsável pelo Sistema de Controle Interno.

\section{Conclusão}

O controle interno é indispensável para a concretização da transparência na gestão do gasto público. É também parte integrante e ativa do ciclo de gestão do governo, prevenindo irregularidades, integrando-se e facilitando o trabalho do controle externo exercido pelo Poder Legislativo, contribuindo para o alcance de uma boa governança pública, a promoção da ética e da transparência e a redução de vulnerabilidades e riscos de ocorrência da corrupção.

A Prefeitura Municipal de Três Rios possui um sistema de controle interno constituído e procura executar as atividades inerentes a esse controle. As atividades são desenvolvidas na Secretaria de Controle Interno, sendo vinculada diretamente ao prefeito, dando suporte para a supervisão do dia a dia. Segundo as informações coletadas nesta pesquisa, os mecanismos e os procedimentos de controle interno adotados são relevantes para o desenvolvimento das atividades de gestão da prefeitura, onde são considerados norteadores para evitar erros que podem ferir os princípios da Administração Pública e causar danos à população.

Entretanto, notou-se que as atividades de auditoria e controladoria que, atualmente, são exercidas pela mesma unidade embora a auditoria deva ser realizada por unidade administrativa diferente da unidade que organiza os controles. Sugere-se, neste sentido, uma bipartição da denominada Secretaria de Controle Interno em dois departamentos: a Controladoria e a Auditoria. A organização dos controles internos seria feita pela controladoria e a auditoria pelo departamento de Auditoria, em alinhamento ao princípio da segregação de funções.
Observou-se que a secretaria do município necessita de mais pessoal e mais qualificação. Tal necessidade se justifica para que a atuação do controle interno seja realizada antes, durante e depois dos atos administrativos, com a finalidade de acompanhar o planejamento realizado, garantir a legitimidade frente aos princípios constitucionais, verificar a adequação às melhores práticas de gestão e garantir que os dados contábeis sejam fidedignos. Um controle interno forte, atuante, com servidores bem preparados, respalda e resguarda a atuação do administrador, dificulta a ocorrência de irregularidades e resulta em uma melhor aplicação dos recursos públicos.

A ação do Poder Legislativo municipal na fiscalização dos gastos públicos é fundamental para garantir que a sua aplicação esteja de acordo com os interesses coletivos. É importante salientar que a Câmara quando controla a atuação do gestor público municipal está, na verdade, cumprindo uma obrigação fixada pelo texto da Constituição Federal Brasileira de 1988, a qual estabelece em seu art. 31 que a fiscalização do município será exercida pelo Poder Legislativo Municipal, mediante controle externo.

Pode-se observar que a população pesquisada na Câmara compreende que o controle interno é importante para a Administração Pública, mas não conhece profundamente as rotinas exercidas por ele. Embora em algumas situações possa se demonstrar necessário ter conhecimentos técnicos sobre determinados assuntos, há diversos pontos cujo controle é bem menos complexo e que, por conseguinte, pode facilmente ser realizado. Por exemplo, a verificação entre a compatibilidade dos inventários da prefeitura e a existência física de um bem ou a adequação dos controles do uso dos veículos oficiais.

Foi possível constatar que a maioria dos participantes acredita que a maior dificuldade em implantar o controle interno deve-se a falta de esclarecimento quanto a sua importância gerencial e legal. O controle interno na área pública é de extrema importância para garantir a padronização dos procedimentos de controle e a "memória" do órgão ou entidade, independente da manutenção ou troca dos servidores que o operacionalizam, bem como dos gestores aos quais as informações são prestadas.

O controle interno atuando de forma independente e com métodos e técnicas que envolvem procedimentos 
típicos, em função de suas atribuições constitucionais e legais, desempenha papel relevante na Administração Pública e deve ser entendido de forma ampla, isto é, não está limitado apenas aos aspectos financeiros e administrativos, pois compreende todo o conjunto de métodos e ações implementados dentro de determinado órgão administrativo, criando uma cultura de transparência, visando assegurar eficiente arrecadação das receitas e adequado emprego dos recursos públicos. Bem como, efetuando comparação entre os resultados previstos e os realizados em sintonia com o interesse público.

Torna-se relevante evidenciar que esta pesquisa, em função de suas peculiaridades e limitações próprias, não pretendeu esgotar o tema em questão e nem tampouco alcançar respostas para todos os questionamentos que a problemática suscitou. Mas, apresentar uma análise e uma maior reflexão e discussão com base na literatura pertinente sobre a importância do controle interno na Administração Pública.

No entanto, constata-se que o objetivo traçado no início do trabalho foi alcançado, pois foram identificados os procedimentos e ferramentas de controle interno utilizados pela prefeitura de Três Rios.

Como sugestão, outros pesquisadores podem realizar um novo estudo para verificar se as outras secretarias da prefeitura de Três Rios conhecem o Sistema de Controle Interno e se exercem suas atividades com base nos preceitos legais. E/ou um novo estudo com uma abrangência maior de servidores. Para um estudo mais completo, sugere-se utilizar vários municípios em um único estudo, a fim de traçar um perfil mais detalhado da realidade dos municípios fluminenses.

\section{Referências}

AICPA - American Institute of Certified Public Accountants. Disponível em: <http://www.aicpa. org/Pages/default.aspx>. Acesso em: 14 de fev. 2014

ALMEIDA, M. de S. (2011). Elaboração de projeto, TCC, dissertação e tese: uma abordagem simples, prática e objetiva. $1^{a}$ Ed. São Paulo: Atlas.

BRASIL (1946) Constituição federal de 1946 - Artigo $\mathrm{n}^{\circ} 77$, de 18 de setembro de 1946. Disponível em: http://www.interlegis.gov.br.

ATTTIE, W. (2011). Auditoria: Conceitos e aplicaçoes. 6. ed. São Paulo: Atlas.

BARRETO, M. da G. P. (2008). Controladoria na Gestão: a relevância dos custos da qualidade. São Paulo: Saraiva.

BOTELHO, M. M. (2003). Manual de Controle Interno - Teoria \& Prática - Um Enfoque na Administração Pública Municipal. Curitiba: Juruá.

BRASIL (1922). Decreto $n^{\circ} 4.536$, de 28 de janeiro de 1922. Dispõem sobre a organização o Código de Contabilidade da União. Disponível em: http://www. interlegis.gov.br.

BRASIL (1964). Lei no 4.320, de 17 de marco de 1964. Estatui Normas Gerais de Direito Financeiro para elaboração e controle dos orçamentos e balanços da União, dos Estados, dos Municípios e do Distrito Federal. Disponível em: http://www.interlegis.gov.br.

BRASIL (1967). Decreto-Lei 200, de 25 de fevereiro de 1967. Dispõe sobre a organização da Administração Federal, estabelece diretrizes para a Reforma Administrativa e dá outras providências. Disponível em: http://www.interlegis.gov.br.

BRASIL (2000). Lei Complementar n. ${ }^{\circ} 101$, de 04 de maio de 2000. Estabelece normas de finanças públicas voltadas para a responsabilidade na gestão fiscal e dá outras providências. Disponível em: http://www. interlegis.gov.br.

BRASIL (2001). Instrução Normativa $n^{\circ} 01$, de 06 de abril de 2001. Define diretrizes, princípios, conceitos e aprova normas técnicas para a atuação do Sistema de Controle Interno do Poder Executivo Federal. Disponível em: http://www.interlegis.gov.br.

BRASIL (2009). Constituição (1988) Constituição da República Federativa do Brasil. São Paulo: Rideel.

CALIXTO, G. E \& VELASQUEZ, M. D. P. (2005). Sistema de Controle Interno na Administração Pública Federal. In: Revista Eletrônica de Contabilidade. Disponível em: <http://cascavel.ufsm.br/revistas/ ojs-2.2.2/index.php/contabilidade/article/ view/63/3660>. Acesso em: 14 de fev. 2014. 
Campos, N. M. de, Pinto, R. S. \& Mello, S. P. T. de. (2010). Treinamento e Desenvolvimento: Uma Análise do Programa de Capacitação dos Servidores do Instituto Federal de Educaşão, Ciência e Tecnologia Sul-Rio-Grandense. Mar del Plata. Disponível em: <http://www. inpeau.ufsc.br/wp/wp-content/BD_documentos/ coloquio10/204.pdf>. Acesso em: 20 de mar. 2014.

CARVALHO Filho, J. dos S. (2009). Manual de Direito Administrativo. 21ª edição. Rio de Janeiro. Lumen Juris.

CASTRO, D. P. de. (2008). Auditoria e Controle Interno na Administração Pública. Evolução de Controle Interno no Brasil: do Código de Contabilidade de 1922 até a Criação da CGU em 2003. São Paulo: Atlas.

CASTRO, D. P. de. (2011). Auditoria, Contabilidade e Controle Interno no Setor Público: integração das áreas do ciclo de gestão: contabilidade, orçamento e auditoria e organização dos controles internos, como suporte à governança corporativa. $4^{a}$ Ed. São Paulo: Atlas.

CFC - Conselho Federal de Contabilidade. Resolução n. 820 de 1997. Disponível em: <www.cfc.org.br/ sisweb/sre/docs/RES_820.doc>. Acesso em: 14 de fev.2014.

COELHOS, R. C. (2009). O Público e o Privado na Gestão Pública. Florianópolis: Departamento de Ciências da Administração / UFSC; [Brasília]:

CAPES: UAB.

COSO - Committee of Sponsoring Organizations of the Treadway Commission. Disponível em: <http:// www.coso.org >. Acesso em: 14 de fev. 2014.

CREPALDI, S. (2007). Auditoria contábil teoria e prática. 4. ed. São Paulo: Atlas.

DI PIETRO, M. S. Z. (2005) Direito administrativo. $16^{a}$ ed. São Paulo: Atlas.

GIL, A. C. (2008) Métodos e Técnicas de Pesquisa Social. $6^{a}$. ed. São Paulo: Atlas.

IAIB - Instituto dos Auditores Internos do Brasil. Disponível em: <http://www.iiabrasil.org.br/new/ quemsomos.html>. Acesso em: 14 de fev. 2014.

INTOSAI - International Organization of Supreme Audit Institutions. Disponível em: < http:/ /www. intosai.org/about-us.html>. Acesso em: 14 de fev. 2014.

JOSÉ FILHO, A. (2008) A Importância do Controle Interno na Administração Pública. DIVERSA.

Teresina, ano 1, no. 1, p. 85-99.

MOSSIMANN, C. P.; FISCH, S. (1999) Controladoria: seu papel na administração de empresas. $2^{\mathrm{a}}$ edição. São Paulo: Atlas.

SILVA, L. M. da. (2004) Contabilidade governamental.7.ed. São Paulo: Atlas.

SOUZA, C. S. de. (2008) O papel do controle interno na gestão dos gastos municipais. Curitiba: FAE. 